Rev Esp Casos Clin Med Intern (RECCMI). 2020 (Ago); 5(2): 90-92

\title{
Neumonía bilateral y afectación hepática por COVID-19
}

Jairo Luque-del Pino, Cristina Asencio-Méndez, Francisco Navarro-Romero, Victoria Núñez-Rodríguez, Francisco Moreno-Martínez Servicio de Medicina Interna. Hospital Costa del Sol. Marbella (Málaga). España

\section{Recibido:08/06/2020}

Aceptado: 03/07/2020

En línea: 31/08/2020

Citar como: Luque-del Pino J, Asencio-Méndez C, Navarro-Romero F, Núñez-Rodríguez V, Moreno-Martínez F. Neumonía bilateral y afectación hepática por COVID-19. Rev Esp Casos Clin Med Intern (RECCMI). 2020 (Ago); 5(2): 90-92. doi: 10.32818/reccmi.a5n2a12.

Cite this as: Luque-del Pino J, Asencio-Méndez C, Navarro-Romero F, Núñez-Rodríguez V, Moreno-Martínez F. Bilateral pneumonia and liver disease by COVID-19. Rev Esp Casos Clin Med Intern (RECCMI). 2020 (Ago); 5(2): 90-92. doi: 10.32818/reccmi.a5n2a12.

Autor para correspondencia: Jairo Luque-del Pino. jairo_malaga@hotmail.com

\begin{tabular}{l} 
Palabras clave \\
\hline COVID \\
$\triangleright$ COVID-19 \\
$\triangleright$ Neumonía \\
$\triangleright$ Enfermedad hepática \\
\hline Keywords \\
\hline$\triangleright$ COVID \\
$\triangleright$ COVID-19 \\
$\triangleright$ Pneumonia \\
$\triangleright$ Liver disease \\
\hline
\end{tabular}

\section{Resumen}

La infección por coronavirus SARS-CoV-2 representa una nueva enfermedad llamada COVID-19. Presentamos el caso de un varón de 40 años con neumonía bilateral y afectación hepática por COVID-19.

\section{Abstract}

The infection by coronavirus SARS-COV-2 is a new disease named COVID-19. We present the case of a 40 yearold man with bilateral pneumonia and liver disease by COVID-19.

\section{Puntos destacados}

$\triangleright$ La COVID-19 es una enfermedad sistémica con afectación hepática en el $14-53 \%$ de los pacientes hospitalizados.

$\triangleright$ La hipertransaminasemia en pacientes COVID-19 es más frecuente en varones y se asocia con mayor riesgo de progresión a una enfermedad severa.

\section{Introducción}

En diciembre de 2019 aparecieron en Wuhan (China) los primeros casos de neumonía originados por una nueva cepa de coronavirus (SARS-CoV-2), la nueva enfermedad se denominó COVID-19. El 31 de enero se registró el primero caso importado en España y el 26 de febrero el primer contagio local. El 11 de marzo se declaró la pandemia por la Organización Mundial de la Salud (OMS). A fecha 10 de mayo de 2020, se habían comunicado en el mundo 3.986 .119 casos, de los que 278.814 habían fallecido'; España era el segundo país del mundo con más casos notifcados: 224.390 casos confirmados, con 26.621 fallecidos y 136.166 curaciones². $^{2}$

Como es una nueva enfermedad, la notificación de casos de presentación clínica atípica y manejo terapéutico complejo resulta útil para profundizar en conocer mejor la enfermedad, de la mano de los ensayos clínicos y grandes estudios observacionales puestos en marcha.

\section{Caso clínico}

\section{Antecedentes}

Varón de 40 años con dispepsia por Helicobacter pylori positivo erradicado e intervenido de colecistectomía. No presentaba hábitos tóxicos ni tomaba ningún tratamiento. Natural de Ecuador y trabajador de la construcción, vivía con tres personas en domicilio y negaba contacto con casos confirmados o sospechosos de COVID-19.

Acudió a Urgencias el 3 de abril de 2020 refiriendo un cuadro clínico de 7 días de evolución consistente en fiebre de hasta $41^{\circ} \mathrm{C}$, odinofagia, artromialgias, dolor abdominal con náuseas/vómitos y diarrea sin productos patológicos. Durante las últimas 48 horas asociaba, además, tos seca, dolor pleurítico y dificultad respiratoria a moderados esfuerzos.

\section{Exploración física}

Tensión arterial: 152/86 mmHg. Frecuencia cardíaca: 94 lpm. Frecuencia respiratoria: 22 rpm. Temperatura: 37,7 ㄷ. Saturación de oxígeno basal 96\%. Aceptable estado general, bien hidratado y perfundido, eupneico en reposo. Auscultación cardíaca con tonos rítmicos sin soplos. Auscultación pulmonar con murmullo vesicular sin ruidos sobreañadidos. Abdomen anodino. Sin focalidad neurológica. 


\section{Pruebas complementarias}

Se realizaron las siguientes pruebas complementarias:

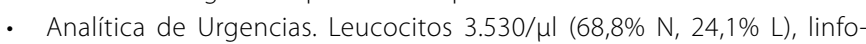
citos absolutos $850 / \mu \mathrm{l}$, hemoglobina $14,7 \mathrm{~g} / \mathrm{dl}$, plaquetas $146.000 / \mu \mathrm{l}$. INR 1,07, TTPA 27,9 s y dímero-D $363 \mathrm{ng} / \mathrm{ml}$. Glucosa $123 \mathrm{mg} / \mathrm{dl}$, creatinina $0,98 \mathrm{mg} / \mathrm{dl}$, filtrado glomerular $96 \mathrm{ml} / \mathrm{min}$ por CKD-EPI, GOT $154 \mathrm{U} /$, GPT $178 \mathrm{U} /$, bilirrubina total 0,5 mg/dl, LDH $395 \mathrm{U} / \mathrm{l}, \mathrm{Na} 136 \mathrm{mEq} / \mathrm{l}, \mathrm{K}$ 4,1 $\mathrm{mEq} / \mathrm{l}, \mathrm{PCR} 56,3 \mathrm{mg} / \mathrm{l}$, procalcitonina 0,07 $\mathrm{ng} / \mathrm{ml}$.

- Microbiología. PCR SARS-CoV-2 positiva en esputo. Antigenuria de neumococo y Legionella negativos. Urocultivo y hemocultivos negativos.

- Radiografía de tórax. Índice cardiotorácico normal. Opacificaciones parcheadas bilaterales de predominio periférico sugerentes de neumonía por COVID-19 (Figura 1).

- Electrocardiograma (ECG) en Urgencias. Ritmo sinusal a 70 lpm y QTC dentro de la normalidad.
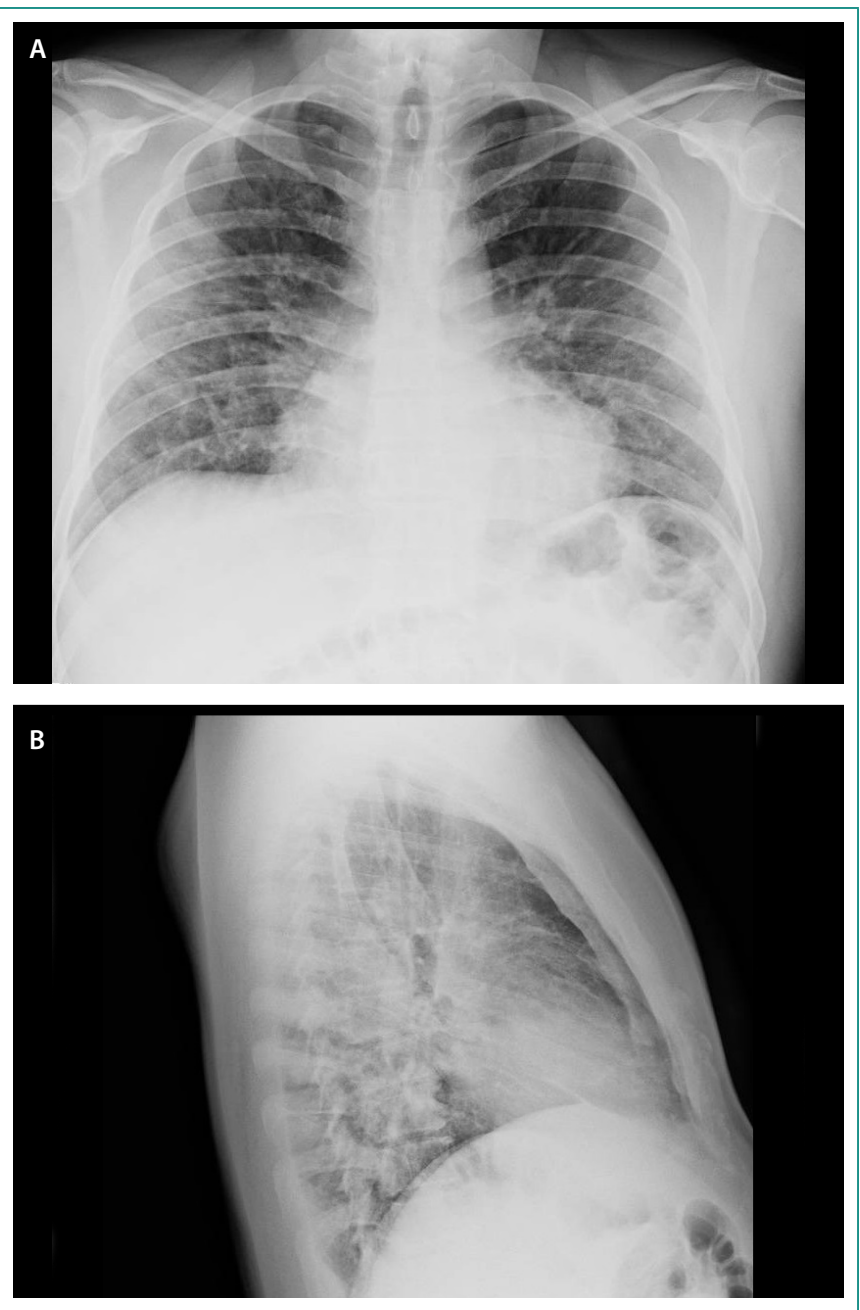

Figura 1. Radiografía de tórax posteroanterior (A) y lateral (B). Opacificaciones parcheadas bilaterales de predominio periférico sugerentes de neumonía por COVID-19

\section{Evolución}

Ante la estabilidad clínica del paciente se decidió alta domiciliaria con azitromicina (500 mg dosis de carga, seguido de 250 mg/24 h durante 5 días), hidroxicloroquina (200 mg/8 h durante 5 días), recomendando realizar ECG de control en su centro de salud en 48 horas para monitorización del intervalo QT.
Dos días después del alta de Urgencias se contactó telefónicamente con el paciente, el cual refería que continuaba con fiebre y tos seca con dolor pleurítico, así como aparición de dificultad respiratoria a mínimos esfuerzos a pesar de llevar 2 días de tratamiento. De modo que se le indicó acudir nuevamente a Urgencias.

En la exploración, el paciente presentaba $38,4{ }^{\circ} \mathrm{C}$ y saturación basal del $92 \%$, con buen estado general y eupneico en reposo, aunque con auscultación de crepitantes en ambas bases. En la analítica destacaba mayor linfopenia (510 linfocitos/ $\mu$ l), niveles de LDH (778 U/I) y dímero-D (616 ng/ $\mathrm{ml})$, así como mayor nivel de transaminasas: GOT $460 \mathrm{U} / \mathrm{l}$ (5-39) y GPT 569 U/I (5-40). No obstante, la PCR continuaba en $43,7 \mathrm{mg} / \mathrm{dl}$ y la procalcitonina negativa $(<0,5 \mathrm{ng} / \mathrm{ml})$. La radiografía de tórax destacaba empeoramiento de las opacidades parcheadas bilaterales de predominio periférico. Por todo ello, se decidió ingreso hospitalario, manteniendo el tratamiento con azitromicina e hidroxicloroquina y heparina de bajo peso molecular a dosis profilácticas (Figura 2).

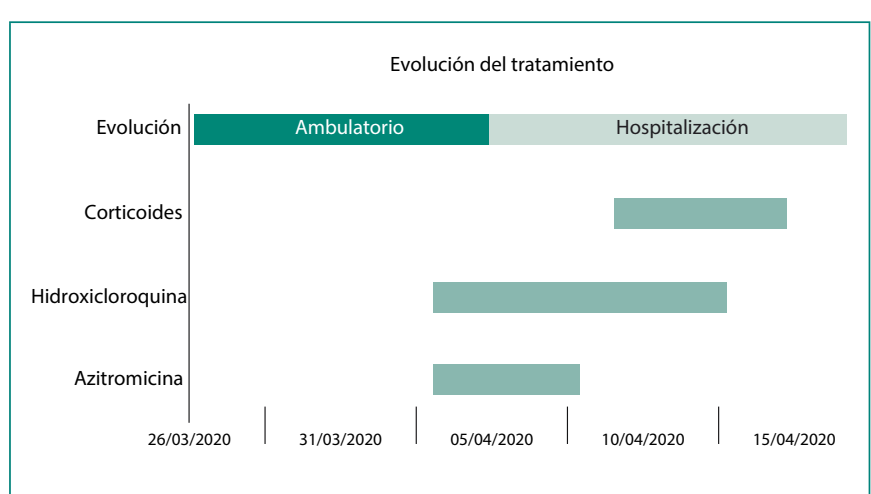

Figura 2. Evolución del tratamiento del paciente

Se completó el estudio analítico con ferritina de 2.600 ng/ml, IL-6 de 52 pg/ml, serología de VHB, VHC y VIH que resultaron negativas, y Quantiferon ${ }^{\circledR}$ TB GOLD que fue positivo. Además, se realizó tomografía computarizada (TC) de tórax en la que se objetivaron opacidades en vidrio deslustrado con distribución periférica difusa, con afectación de todos los lóbulos pulmonares, compatible con la sospecha de neumonía por COVID-19 (Figura 3).

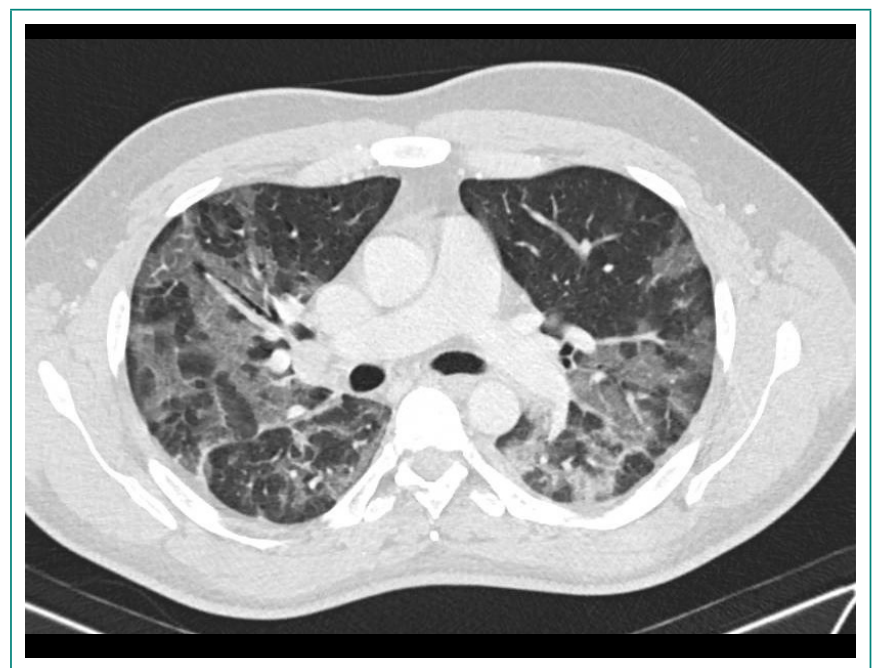

Figura 3. TC de tórax. Opacidades en vidrio deslustrado con distribución periférica difusa, con afectación de todos los lóbulos pulmonares con tendencia a la condensación en lóbulo inferior izquierdo, compatible con la sospecha de neumonía por COVID-19 
Ante el deterioro clínico, analítico y radiológico del paciente, se replanteó la actitud terapéutica. En nuestro centro se había agotado el interferón y no podíamos contar con este fármaco. El paciente llevaba 11 días de evolución, por lo que se desestimaron lopinavir/ritonavir y remdesivir, al haber concluido la fase inicial de replicación viral. Por ello se pensó en emplear un fármaco con eficacia en la fase de respuesta inflamatoria de la infección: tocilizumab y corticoides. No obstante, el tocilizumab se descartó ante la presencia de tuberculosis latente y por los niveles de transaminasas, que superaban $\times 5$ el valor de la normalidad. Por tanto, se inició metilprednisolona en dosis de 0,5 mg/kg/12 h y dosis descendente durante 7 días.

El paciente evolucionó favorablemente desde el punto de vista clínico, con saturación de oxígeno basal al alta del 96\% y manteniendo sólo un leve dolor pleurítico en el momento del alta el 16 de abril. Igualmente presentó mejoría radiológica y analítica, con normalización de las cifras de linfocitos totales $(2.200 / \mu l)$ y de dímero-D (199 ng/ml), descenso de la ferritina (de 2.600 a $1.440 \mathrm{ng} / \mathrm{ml}$ ) y de la GPT (de $569 \mathrm{U} / \mathrm{l}$ a $370 \mathrm{U} / \mathrm{l}$ ), así como la normalización de la GOT (35 U/I).

\section{Diagnóstico}

Neumonía bilateral y afectación hepática por infección confirmada por COVID-19.

\section{Discusión y conclusión}

La COVID-19 es una enfermedad sistémica en la que el virus SARS-CoV-2 se une a los receptores de la enzima convertidora de angiotensina presente en múltiples localizaciones (pulmón, hígado, intestino, riñón, corazón y endotelio vascular).

La lesión hepática asociada a COVID-19 se define como cualquier daño hepático que ocurra durante la progresión de la enfermedad y/o el tratamiento en pacientes con o sin enfermedades hepáticas preexistentes. La alteración hepática, principalmente la elevación de GOT y GPT, es más frecuente en varones y suele ser más severa en pacientes con afectación grave por COVID-19 observándose en el 2-11\% de todos los pacientes con COVID-19 y en el 14-53\% de los pacientes hospitalizados 3 . Sólo el 2-11\% de los pacientes con alteración hepática presentaban enfermedad hepática previa.

No se han documentado casos de fallecimiento por insuficiencia hepática aguda en la COVID-19². La biopsia hepática de pacientes fallecidos por
COVID-19 grave mostraron esteatosis microvascular moderada, así como una actividad lobular y portal leves, de probable origen multifactorial: daño inmunitario mediado debido a la respuesta inflamatoria severa (ferritina, IL-6, dímero-D, PCR), citotoxicidad directa debido a la replicación viral activa en células hepáticas, anoxia, daño hepático inducido por fármacos (lopinavir/ ritonavir, remdesivir, tocilizumab, etc.), reactivación de enfermedad hepática preexistente, entre otros ${ }^{5}$.

Un estudio en China con 417 pacientes con COVID-19 mostró que el 76,3\% presentó alteración de las pruebas hepáticas y que los pacientes con patrón hepatocito y mixto (hipertransaminasemia sin colestasis) tenían mayor riesgo de progresar a una enfermedad severa (OR 2,73; IC 95\% 1,19-6,3)

Por todo ello, es fundamental monitorizar la función hepática en pacientes con COVID-19, así como investigar otras causas de enfermedad hepática subyacentes. Aún no disponemos de datos sobre la seguridad de los medicamentos utilizados actualmente en el tratamiento del SARS-CoV-2, por lo que los ensayos clínicos en curso resultan cruciales sobre la eficacia y toxicidad de los diferentes tratamientos potenciales empleados en la COVID-19.

\section{Bibliografía}

1. Informe sobre el reporte de casos de COVID-19 (Internet). ECDC; 2020 abr (citado 10 de mayo de 2020). Disponible en: https://qap.ecdc.europa.eu/ public/extensions/COVID-19/COVID-19.html

2. Actualización n. 101. Enfermedad por el coronavirus (COVID-19). 10.05.2020 (datos consolidados a las 21:00 horas del 09.05.2020) (Internet). Ministerio de Sanidad, Gobierno de España; 2020 abr (citado 29 de abril de 2020). Disponible en: https://www.mscbs.gob.es/profesionales/ saludPublica/ccayes/alertasActual/nCov-China/documentos/Actualizacion_101_COVID-19.pdf

3. Guan WJ, Ni ZY, Hu Y, Liang WH, Ou CQ, He JX, et al. Clinical characteristics of coronavirus disease 2019 in China. N Engl J Med. 2020; 382(18): 1708-1720. doi: 10.1056/NEJMoa2002032.

4. Lee IC, Huo TI, Huang YH. Gastrointestinal and liver manifestations in patients with COVID-19. J Chin Med Assoc. 2020; 83(6): 521-523. doi: 10.1097/ JCMA.0000000000000319.

5. Sun J, Aghemo A, Forner A, Valenti L. COVID-19 and liver disease. Liver Int. 2020; 40(6): 1278-1281. doi: 10.1111/liv.14470.

6. Cai Q, Huang D, Yu H, Zhu Z, Xia Z, Su Y, et al. COVID-19: abnormal liver function tests. J Hepatol. 2020 Apr 13; S0168-8278(20)30218-X. doi: 10.1016/j.jhep.2020.04.006. 